\title{
Model of multiple-layer pavement structure-subsoil system
}

\author{
M. KADELA* \\ Building Research Institute, 1 Filtrowa St., 00-611 Warsaw, Poland
}

\begin{abstract}
Progress made in recent years has brought about a high demand for increasingly modern structural and technological solutions. Each structure should in turn be designed and built to show sufficient durability for the intended period of use. The requirement of durability is met if, throughout its intended lifetime, the structure fulfils its roles regarding load-bearing capacity, serviceability limits and stability without excessive, unexpected costs. Due to the above, a need arises to predict the response of an engineering structure to given loads throughout its life. Thus it becomes increasingly common to employ numerical analyses using the finite elements method (FEM), both on the design stage and later, for the purposes of evaluating the state of a specific structure. However, a numerical calculation model may be constructed in different ways. This paper presents the impact of geometry of the model, the choice of a discretization mesh and the choice of a continuous 3D or 2D model corresponding to pavement-subgrade system calculation model. 3-dimensional modelling was carried out in this paper as full modelling of actual engineering problems in 3-dimensional space, and in the form of simplified modelling using axial symmetry. In the model, a traditional multi-layer pavement structure was considered. Criterion values obtained in numerical analyses were compared to values obtained with the use of VEROAD software.
\end{abstract}

Key words: road pavement, mechanical methods, multi-layer structure, calculation model, finite element analysis (FEA).

\section{Introduction}

The past fifty years saw sudden progress in the field of assessing and predicting the behavior of materials, construction elements or entire structures with the use of appropriate calculation methods. This fact is related to, on the one hand, the growing needs brought about by large projects such as underground structures $[1,2]$, tower structures, heavy industrial buildings, large tanks and storage yards, highways and large bridges [3, 4], and on the other $[5,6]$ - to the development of equipment, research procedures and test result interpretation methods, as well as restricted possibilities of conducting full scale tests on site (mainly due to time constraints and the costs of the projects themselves). Another factor that has contributed to this process was the development of potential to execute large endeavors, which has grown together with engineering and calculation technology related to numerical modelling of the issues in question.

The progress of mechanics and computer science, in particular in the field of calculation software, has contributed to the application of finite element analysis (FEA) in evaluating the structure and subgrade response to the defined loads [7-9], and its increasingly widespread use in the process of designing and evaluating the bearing capacity and serviceability of all kinds of engineering structures. It became the basis for numerous analyses concerning fatigue life of construction elements and entire structures. Application of numerical calculations is also justified considering the growing need for analyses of structure-substrate system behavior in order to optimize the costs of construction and evaluate the modification potential of existing buildings,

*e-mail: m.kadela@itb.pl i.e. horizontal or vertical extension, etc. The global trend of transforming issues of reality into problems of mechanics is visible in the approach adopted in Eurocodes. For example, Eurocode 7 introduces a new concept of geotechnical design, which interconnects, among others, the construction law, standards, design and execution instructions, field and laboratory tests, determining loads for the analyzed system and adoption of calculation models. It thus becomes vital to choose the correct procedure which will allow to describe the behavior of the analyzed structure in all predicted phases of its work. Theories of mechanics employed in the evaluation of structure performance involve certain simplifications; they use models which may considerably deviate from the real structure performance, making their practical application difficult. Creation of a full, credible calculation model therefore automatically implies the use of numerical methods in the analyses.

It should be noted that the numerical tool in the form of a numerical calculation model may be ambiguous to some extent, as in general a model may be created in different ways [10]. The differences are mostly influenced by:

- geometry of the calculation model and the manner of applying boundary conditions,

- adoption of constitutive models for materials used for layers of the structures and the subgrade model, as well as selection of their adequate parameters,

- mode of applying the loads in the calculation models $-2 \mathrm{D}$ or $3 \mathrm{D}$.

In this paper, this problem will be illustrated using the example of a calculation model for a multiple-layer pavement structure interacting with the subgrade. This example has been selected due to the fact that, on the one hand, there are unlimited possibilities in research fields, and on the other, it seems 
that the practice of pavement structure design which covers the evaluation of fatigue life is in a certain way behind the progress of knowledge, recommending a model of isotropic layers laid out in elastic halfspace to calculate displacement, strain and stress both in the process of designing a structure and during analyses checking the current state of the surface as well as designing potential overlays.

\section{Creation of a credible calculation model in the analysis of structure and subgrade stress - review}

A theoretical approach to the problem of dimensioning pavement structures originates in the attempt to solve the static problem for Kirchhoff elastic plate lying on Winkler subgrade and in the search for a solution to the plate's static equilibrium equations in polar coordinates. In 1926, H. M. Westergaard adopted this theory for the purposes of concrete pavement design. In this procedure, the model of an elastic plate lying on a Winkler substrate is still used for determining stress, strain and displacement states.

With the advent of heavy vehicles and with the development of road freight, the intensity of the load per wheel considerably increased, which was followed by first theories that allowed to determine the distribution of stress in the road structure and the subgrade. In 1916, the problem of elastic layer on halfspace loaded with a concentrated force was proposed by K. Terezawa and subsequently researched by M. Melan (1918) and K. Marguerre (1931).

In 1943, such double-layered system, loaded with a uniformly distributed force was solved by D. M. Burmister, who provided a numerical solution for deflections in the system. In 1945, Burmister first considered a double-layered slab, and subsequently a multi-layer one resting on a substrate in the form of elastic halfspace. The load from a car tyre is represented as an axially symmetric load on the slab distributed on the wheel surface, and then the problem is reduced to solving a biharmonic equation in cylindrical coordinates for the slab. Other people dealing with the numerical determination of stress in the system in question were Fox as well as Hank and Scrivner [11].

To this day, the model of isotropic layers on elastic halfspace remains the base model in engineering practice, and the calculations of stress and strain are done analytically using specialized software [12-15]. However, in order to apply FEA methods, in which the commonly used terms "analysis on elastic subgrade" or "analysis on elastic halfspace" are not defined, the correct calculation model of the road pavement structure-subsoil system must be used in (3D) of (2D) state. The axially symmetric model, which is a simplification of the model in 3-dimensional space, seems to be the closest to the halfspace solution. Hence its wide application in engineering practice and research work. It is an approach different from modelling building-substrate systems, where mostly flat (2D) deformation states are used. Modelling the pavement-subgrade system in (2D) state seems highly justified not only due to the simplicity and speed of the calculations, but also due to the nature of the

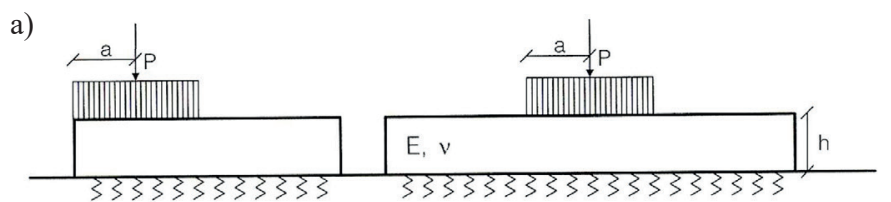

$\mathrm{K}$

b)

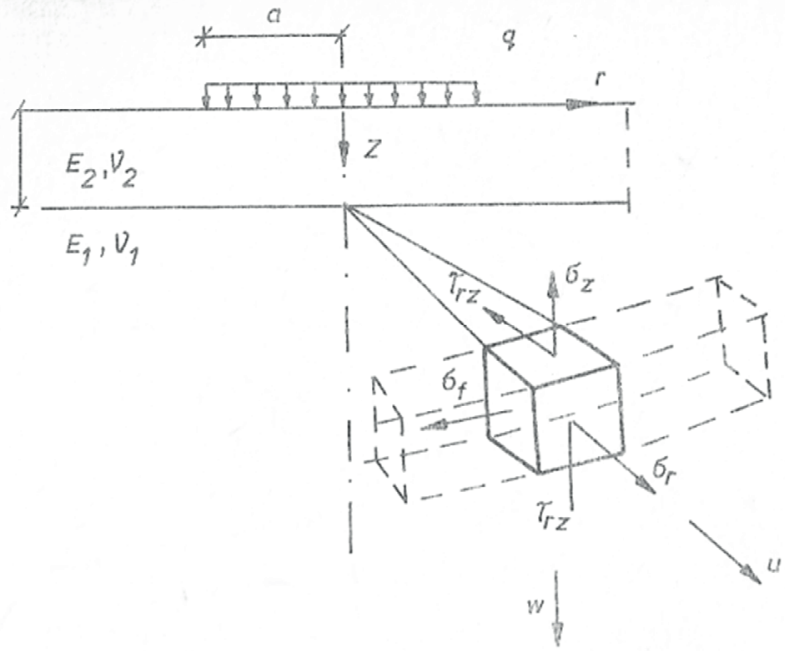

c)

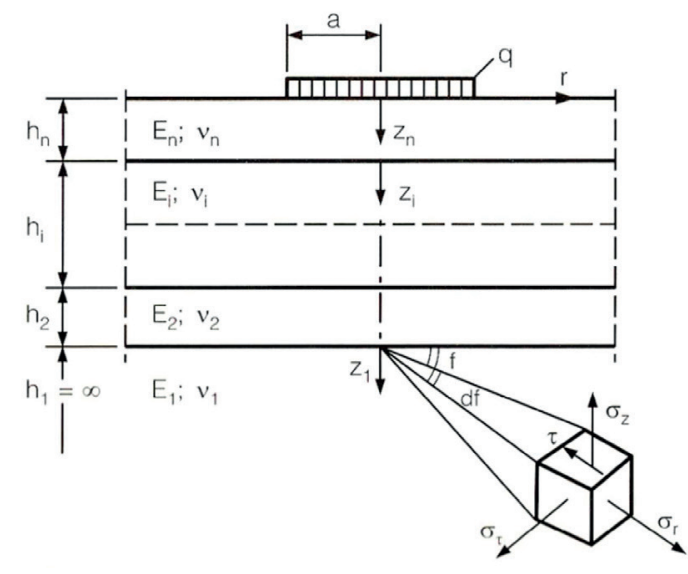

Fig. 1. a) diagram of Westergaard model, b) diagram of double-layered system c) model of layered elastic halfspace [11]

"road" itself, which may be treated as a cross-section cut from infinite space. Application of (2D) state analyses can be found, among others, in $[16,17]$. In literature, the usage of this continuous model is mostly restricted to scientific research, e.g. choosing geosynthetics $[18,19]$ or evaluating the influence of vertical loads resulting from mining activity [20].

Issues of 3-dimensional numerical modelling are presented in literature [21-24]. 3D analyses are mostly employed in modelling specific phenomena [25], the impact of which could have been overlooked or would not be possible to evaluate through analyses using simplified modelling. Examples include assessment of impact of wheels (span and type) on the surface response [26], evaluation of the shape of free side surfaces of structure layers [27], rutting prediction [28, 29] or indirectly related issues such as modelling subgrade reinforcement for embankments [30]. 
Using the assumption that the model of the subgrade under the pavement structure is an elastic halfspace, the area of response to the load is conceptually infinite. In reality, few of the available FEM softwares are equipped with the option of meshes containing infinite elements [31], and that is why it is standard to assume a calculation model of finite dimensions (vertically and horizontally).

There is therefore a need to "cut down" the area of interaction between the subgrade and the slab. This can be done in a variety of ways. The lack of a uniform "recipe" is confirmed by the definition of road subgrade, according to which:

- the subgrade is a zone of native or non-native soil underneath the pavement structure, whose parameters influence the design, execution and usage of the pavement [32]. The subgrade should transfer loads from the layers above it caused by vehicle wheels as well as the impact of weather conditions, in particular the freezing process in the soil [33],

- the subgrade of a pavement is considered to be native or non-native soil down to the freezing depth, and no less than to the depth at which vertical stress from the major live loads is equal to $0.02 \mathrm{MPa}$ [34],

- the subgrade is analyzed to a depth of no less than $1.00 \mathrm{~m}$ under the designed road profile [35],

- subgrade is the zone to a depth of $2.0 \mathrm{~m}$ from the planned level of the embankment [36].

The currently applicable catalogue [37], recommended in reinforcements and repairs of roads, prescribes "to investigate the type and state of soil to a depth of $2.0 \mathrm{~m}$ below the bottom of the pavement structure point in order to determine the bearing group of the subgrade". However, the same catalogue states several pages later that "determining the bearing group of the subgrade requires examination of the type and characteristics of soil to a depth of $1.0 \mathrm{~m}$ below the surface structure". Lack of systematization regarding the depth of subgrade to be analyzed is also visible in foreign standards, catalogues and design guidelines. For example, in France the subgrade is analyzed to a depth of $1.0 \mathrm{~m}$ below the surface of ground works [38], and about $2.0 \mathrm{~m}$ in $[17,24,39]$

According to [40], the maximum thickness of the subgrade involved in the construction of the pavement structure is c. $0.70 \mathrm{~m}$. The zone of "active" subgrade performance equal to $1.0 \mathrm{~m}$ (in the area of direct contact between the subgrade and the structure) is confirmed by field tests carried out on a site consisting of a fragment of actual access road for a storage halls complex [41].

According to [42], when the area of the soil system response has not been precisely detailed, as in the case of the pavement-subbase system, and the boundary conditions are not naturally shaped (e.g. rock, cohesive soil in solid state or highly compressed coarse soil), the dimensions of the model should be chosen in such a manner as not to influence the stress and deformation of the structure resulting from the external load. In literature, the calculation models adopted vary vastly in size, ranging from very large $(H \approx 22.0 \mathrm{~m}$ [43] to very small, with a subgrade that is only $0.15 \mathrm{~m}$ [44] or $0.3 \mathrm{~m}$ [45] thick.

Large calculation areas are recommended e.g. in [27], where, according to the author, sufficient accuracy in calculations of stress and strain was achieved for a model with the dimensions of $7.0 \times 5.0 \mathrm{~m}(\mathrm{AS})$ and $7.0 \times 7.0 \times 5.0 \mathrm{~m}(3 \mathrm{D})$, respectively. Similarly sized calculation areas of $8.6 \mathrm{~m}$ in width and with subgrade of $4.3 \mathrm{~m}$ in thickness have been adopted in [46], and $3.1 \times 235 \times 3.5(3 \mathrm{D})$ in [47]. The author of [48] suggests adopting a calculation model where $B, L=40 r$ and $H=140 r ; r$ being the radius of the load wheel. Thus for $r=0.1565 \mathrm{~m}$, they equal $6.26 \mathrm{~m}$ and $21.91 \mathrm{~m}$, respectively. A similar depth of c. $6.0 \mathrm{~m}$, but a width of $4.0 \div 6.0 \mathrm{~m}$ was adopted in the paper concerning modelling of road ruts [29]. Reference [28] assumes a subgrade of c. $3.0 \mathrm{~m}$ in thickness. Meanwhile, the ILLI-PAVE program, based on the axially symmetric model, adopts a model with a width of $B=12 \mathrm{r}$ and subgrade thickness of $h_{p}=50 \mathrm{r}$ [15]. For a wheel diameter equal to $0.33 \mathrm{~m}$, the model is c. $2.0 \mathrm{~m}$ wide and the subgrade thickness is $8.0 \mathrm{~m}$.

A relatively small area of interaction between the pavement structure and the subgrade, equal to $1.05 \mathrm{~m}$, was adopted in [49] and $0.8 \mathrm{~m}$ in [50]. The MICH-PAVE program, based on axial symmetry, creates a model which is $10 r$ in width and c. $1.15 \mathrm{~m}$ in height, depending on the thickness of the pavement's structural layers [15]. In the case of analyzing a surface with a thin top concrete layer, an area of $0.9 \times 0.9 \times 0.825 \mathrm{~m}$ was adopted [51].

Smaller model dimensions have been taken into consideration in analyses carried out in [52], which adopts a cuboid shape (after taking into consideration bisymmetry of deformation of the analyzed medium) with a size of $0.6 \div 2.1$ m horizontally and $0.15 \div 0.45 \mathrm{~m}$ vertically (subgrade thickness) for the purposes of its 3D model. Similar values are recommended in [53], which suggests using a model with a width of $B=1.2 \div 2.4$ and a height of $H=0.4 \mathrm{~m}$.

Some attempts are also known to "philosophically" transfer the rules of elastic halfspace. An example of this is assuming a subgrade of $1.5 \mathrm{~m}$, and under it an infinite, incompressible layer with a modulus of elasticity $E_{p}=10 \mathrm{GPa}$. Such a rule is applied in Great Britain in so-called functional design [54]. Another solution involves a proposal to close (for problems characterized by circular symmetry) a cylindrical space from underneath on a depth equal to the thickness of structural layers with a half-spherical space of the substrate, achieving convergence of results (including deflections under the load wheel) with a smaller size than in the case of a cylindrical area [13].

There is also yet another way, which consists in assuming, on the bottom base, a displacement proportional to the density of passive pressure according to Winkler's formula $r_{z}=k_{z} \cdot w_{z}$ for $z=h$, where the elastic pressure coefficient of the subgrade is calculated according to (1) [27].

$$
k_{z}=\frac{E^{\prime}}{h^{\prime}},
$$

where:

$E^{\prime}$ - equivalent modulus equal $E^{\prime}=\frac{\left(1-v_{p}\right) \cdot E_{p}}{\left(1+v_{p}\right) \cdot\left(1-2 v_{p}\right)}$,

$h^{\prime}$-equivalent thickness of the subgrade modelled in this manner.

It can therefore be stated that in the case of a pavement structure there is no set definition of subgrade which would allow to unambiguously determine the thickness of the part of 
subgrade interacting with the pavement structure. This presents a significant problem in creating numerical calculation models.

The ambiguity is further emphasized by the need to choose the correct size of the discretization mesh. For example, [21] uses meshes with dimensions of $0.02 \mathrm{~m}$ for axial symmetry analyses and 0.025 for 3D analyses. Meanwhile in [13] it is recommended to use elements with a side of $0.005 \mathrm{~m}$ in order to retain adequate accuracy of calculations using elements with linear shape functions, and 0.02 for elements with parabolic shape functions.

It should be emphasized that the publications concerning the application of numerical calculations using finite element methods for analyzing pavement structure-subgrade systems mention the size of elements only briefly and without detail.

Yet another issue concerns the choice of adequate constitutive relationships [55-57] to describe the behavior of individual layers of the system. Linear elasticity is usually used to evaluate the state of displacement and deformation in literature. This is related to the fact that road construction practice shows that high requirements concerning service parameters of modern road structures can only be met if they perform within the scope of reversible deformations [58].

Research conducted to date [59] indicates that under cyclic loads relatively small deformations appear and increase in the substrate in the initial phase; afterwards the increase stops, and the deformations become fully reversible (so-called reversible deformation state). The phenomenon of soil compaction, and subsequently the elastic phase of subgrade performance is observed in real conditions:

- in tests carried out with a FWD device, for subsequent load drops [60],

- on site, registered after passing of LGVs [61].

This shows the fading of permanent deformations and the structure's entering into the reversible deformation stage, i.e. linearly or non-linearly elastic behavior, which is the basis for assuming elastic relationships to describe the bottom subsystem, representing the subgrade. Solutions using linear elastic relationships can be found e.g. in [27, 39].

Due to the assumption that most structures respond elastically under a single load, it became possible to apply laws formulated for an ideal elastic body, which together with additional assumptions and simplifications (e.g. assuming homogeneous material or static load) allowed to obtain simple mechanistic responses of the pavement under the given load. Assuming that the road structure's performance is limited to reversible deformation also made it possible to eliminate the influence of time on the deformability of materials subject to cyclic loads.

The second state the structure and subgrade may perform in is the elastic-plastic stage. Research using elastic-plastic models, typically the Coulomb-Mohr model, was carried out in $[62,63]$.

Describing the behavior of the structure layer materials and the subgrade using more advanced constitutive models (e.g. Fig. 2) is still rare in engineering practice [64] and applies predominantly to upper layers of the pavement - in subbase

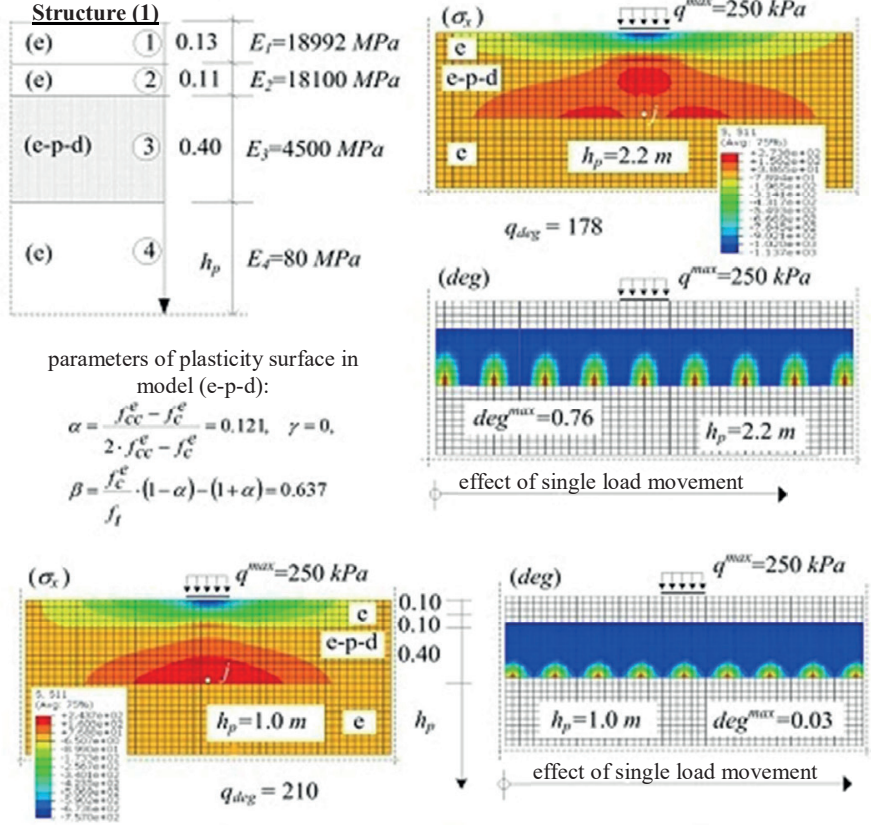

Fig. 2. Evaluation of subbase degradation level [72]

[65-67] and in asphalt layers [68-70]. This fact is related to, on the one hand, lack of investigation of behavior of particular materials in the structure-subgrade system, and on the other - to the complications this causes in the structure design. Those complications include difficulties of describing the materials and subgrade behavior using different softwares and the necessary simplifications in that regard, the necessity to perform advanced laboratory and field tests, and finally the time and costs of performing the calculations themselves.

Therefore, the description of the existing or designed state is still mostly based on linear elasticity. Using elastic relationships to describe the behavior of layers in a pavement structure-subgrade system model using widely accessible FEM software requires unambiguous determination of numerical interaction effects in analyzed subsystems: the layered road structure and the subgrade. This is tied to a detailed analysis of the path of transforming reality into a numerical calculation model. This paper deals with adequacy of the description regarding the contact interaction in the asphalt surface-subgrade system using finite element methods. This task has been carried out by analyzing how the geometry of the road structure-subgrade model influences the values constituting criteria used for designing which employs mechanistic methods, and thus how it influences the fatigue life of the road structure [71].

\section{Calculation model of the pavement-subgrade system}

3.1 Description of the calculation model. Let us consider the effectiveness of simple calculation models using linear elasticity relationships in mechanistic analyses (used in the process of dimensioning road structures, evaluating its bearing capacity 


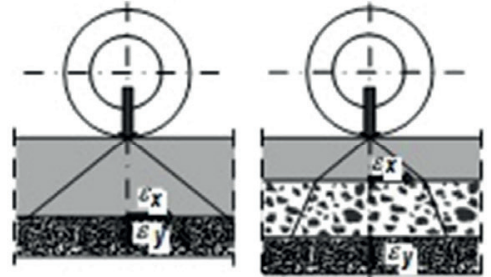

Fig. 3. Characteristic strains defined in layers of road's construction

or reinforcing it) in the light of analyzing the fatigue criteria values (Fig. 3):

- horizontal strain $\varepsilon_{x}$ on the bottom surface of the lowest asphalt layers,

- vertical strain $\varepsilon_{z}$ on the top of natural subgrade,

- tensile strain or stress on the bottom surface of the subbase for semi-rigid pavement,

which allow to evaluate the fatigue life of a road structure for which maximum permissible values have been defined (number of equivalent standard axes $100 \mathrm{kN}$ throughout the designed fatigue life $N_{f}-30$ years for motorways and express roads, 20 years for other road classes).

Maximum vertical displacement directly under wheel load $u_{z}$ was also subject to analysis, and in the case of the base model (Fig. 4) additionally:

- vertical displacement of points on the upper surface $(z=0.0 \mathrm{~m})$, i.e. distribution of deflection,

- vertical displacement of points on the line going through the center of wheel load ( $x=0.0 \mathrm{~m} ; y=0.0 \mathrm{~m})$.

The analysis was carried out for a pavement structure with the layering as shown in Fig. 4.

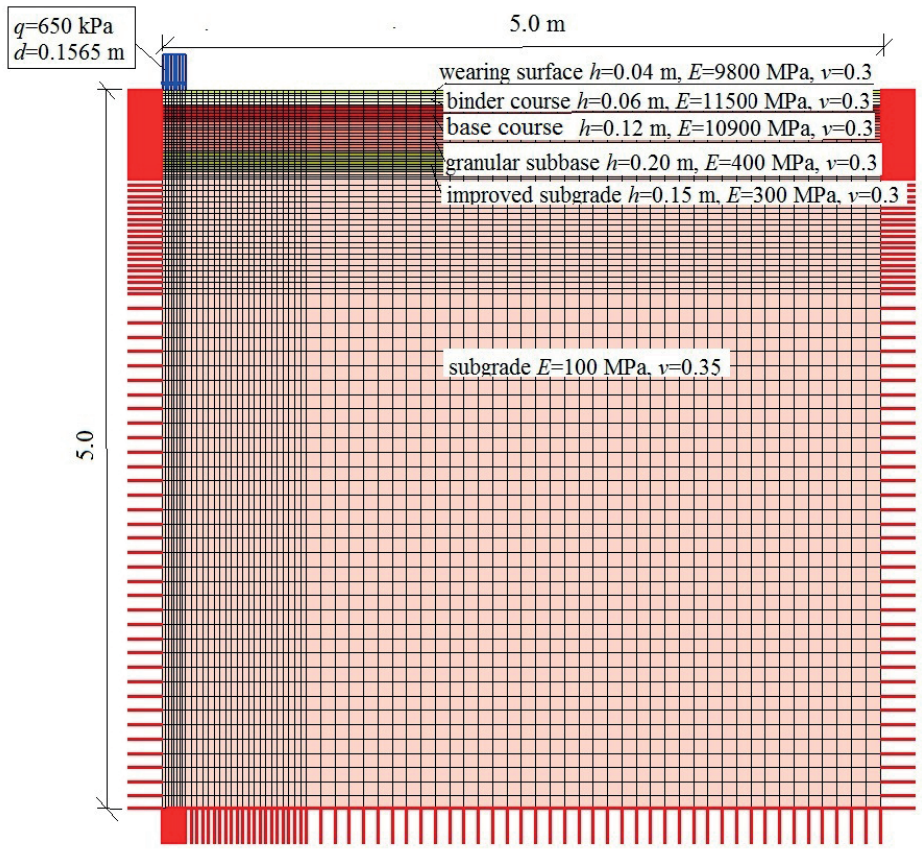

Fig. 4. Finite element model used for analysed layer-construction (axial symmetry); layering of pavement structure [27]
Calculations assume the pavement-subgrade system as a 3-dimensional material continuum consisting of homogeneous, isotropic layers described with linear elastic relationships. The contact between the layers was described using the condition of displacement continuity, which indicates conditions of full bonding between structural layers and the subgrade. The calculation model adopted as a base for the analysis is presented in Fig. 4.

It has been assumed that the load on the surface is that from a standard car wheel, with admissible load per axis $P=100 \mathrm{kN}$. The load has been applied directly to the surface as a uniformly distributed $q$ on the surface of the wheel with a diameter equaling $d$. The model was discretized using a FEM mesh with the smallest element dimension equal to $0.01 \mathrm{~m}(\mathrm{~s} 1)$. It has been assumed that points on the side walls and lower base cannot be subject to displacement perpendicularly. Calculations were carried out with the use of the ZSoil.PC software, which allows to use an appropriate constitutive relationships to describe the behavior of ground (e.g. HSS model, which will be use in future research of pavement structure-subsoil system).

3.2 Results of numerical analyses. The displacement and strain distribution obtained in the process of numerical analyses has been shown on Figs. 5-8 in the form of maps and as a diagram of displacement on the top surface of the pavement $(z=0.0 \mathrm{~m})$ and at a depth under the load $(z=0.0 \mathrm{~m}$ and $x=0.0 \mathrm{~m})$.

The following analyzes were performed to investigate the influence of the choice of continuous 3D or 2D models on the response of a pavement-subgrade system and assessment of the accuracy which can be achieved in the FEM models, the criterion values used in the design and evaluation of existing pavement state.

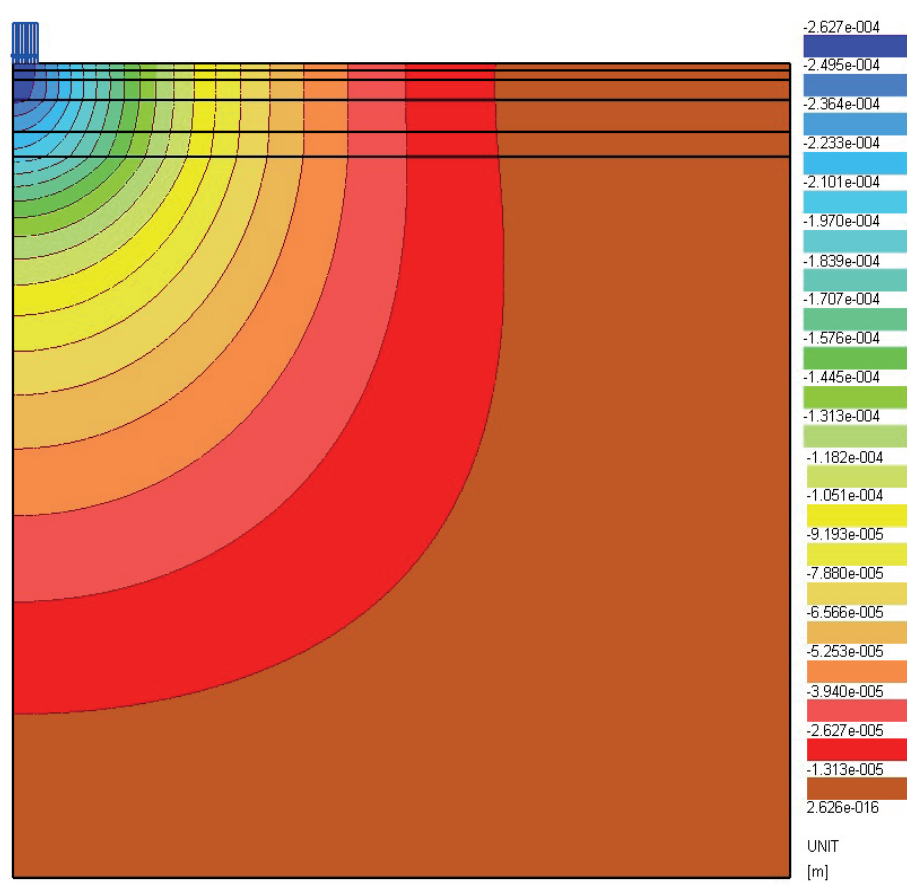

Fig. 5. Distribution of maximum vertical displacement $u_{z}$ 


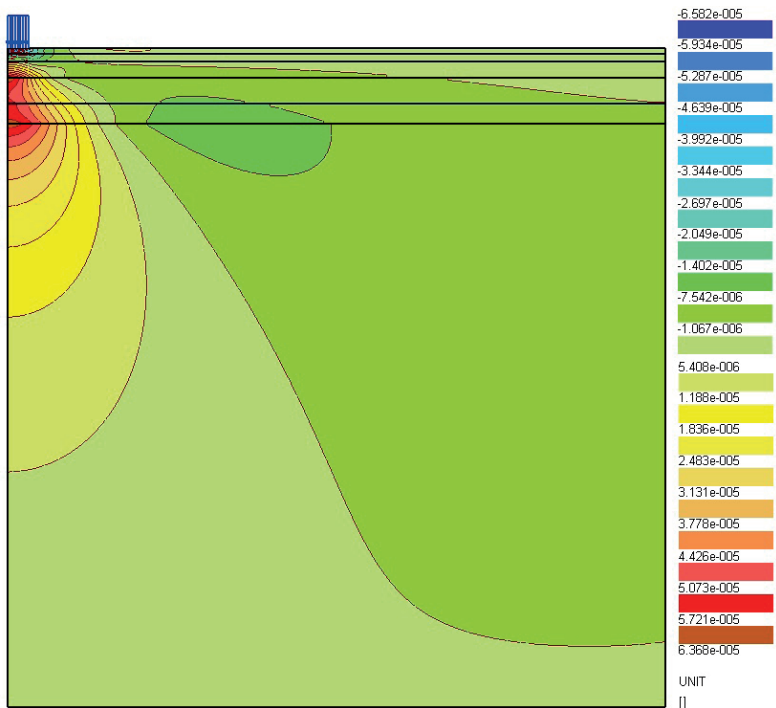

Fig. 6. Distribution of horizontal strain $\varepsilon_{x}$

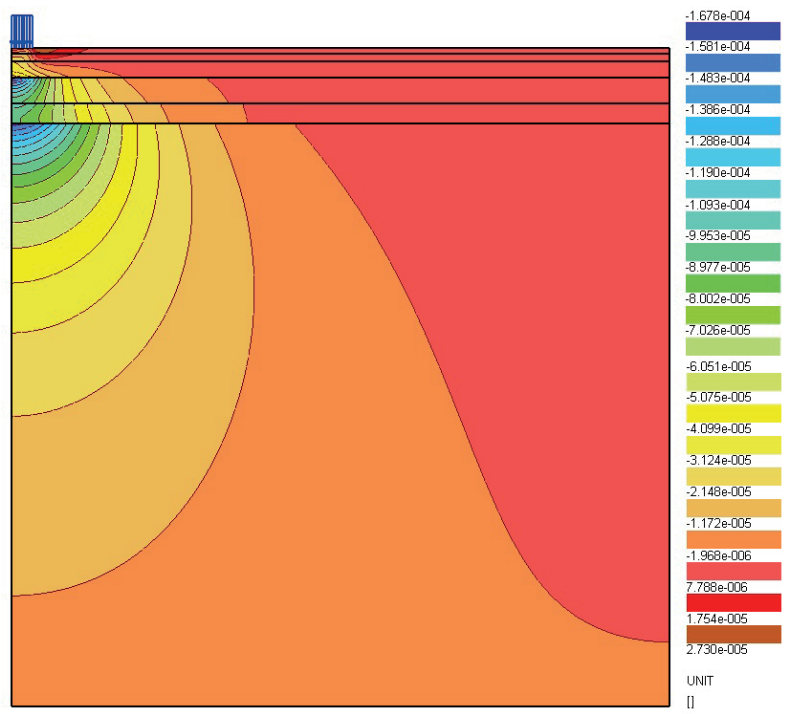

Fig. 7. Distribution of vertical strain $\varepsilon_{z}$

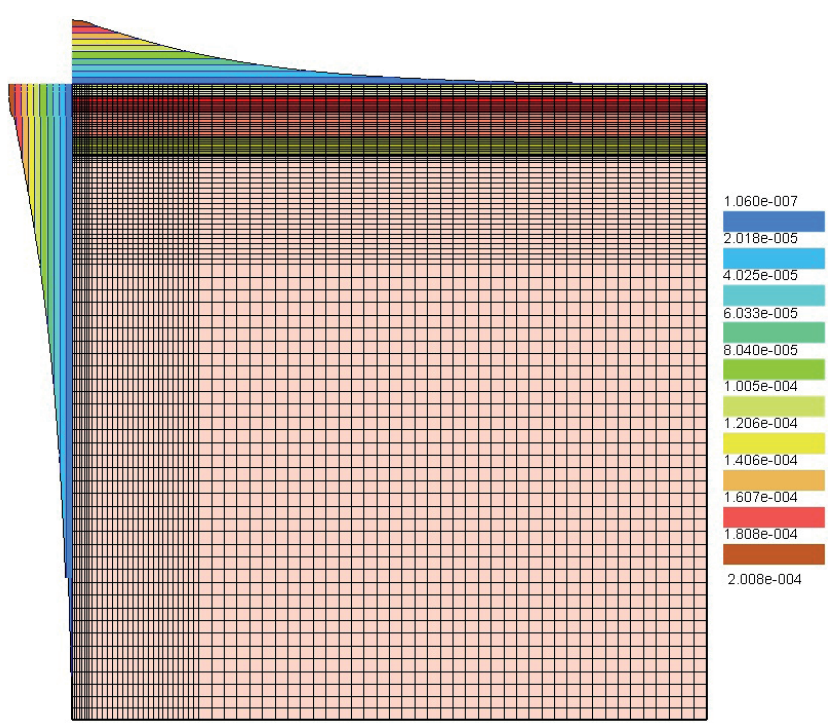

Fig. 8. Distribution of vertical displacement on surface and at model depth
Figures 9 and 10 show distribution of displacement for the model in 2D and fully in 3D. For the 2D analyses, the assumed load was $q^{*}=125 \mathrm{kN} / \mathrm{m}$. The load was chosen through trials to best fit the criteria obtained in the base axially-symmetric model.

The nature (distribution of displacement and strain) of the obtained response of the pavement-subgrade system has been the same but the analyzed values differ depending on the adopted continuous model. The highest values of displacement and vertical strain on the bottom of asphalt layers were obtained for the 2D deformation state. For the axially symmetric and 3-dimensional model these values were almost equal.

However the highest values of horizontal strain on the top of the subgrade was obtained in the analysis for the axially symmetric model and the second highest for the 3-dimensional model, while the lowest was the result for the $2 \mathrm{D}$ deformation

a)

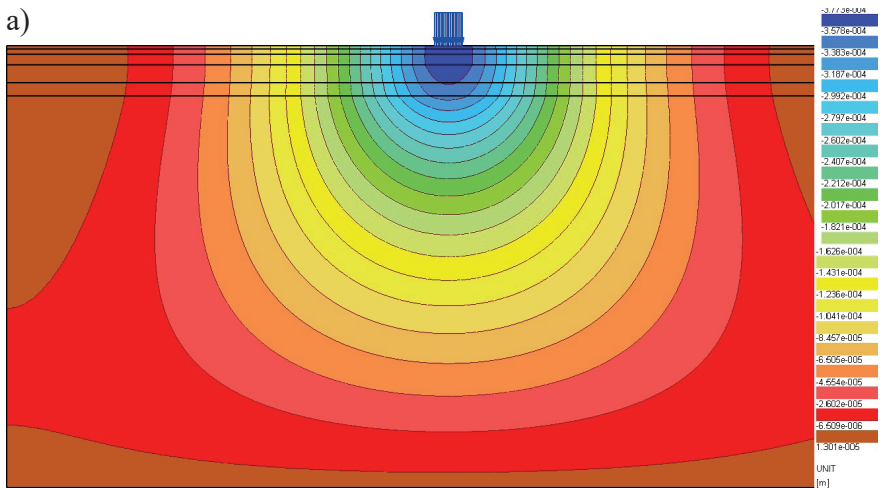

b)

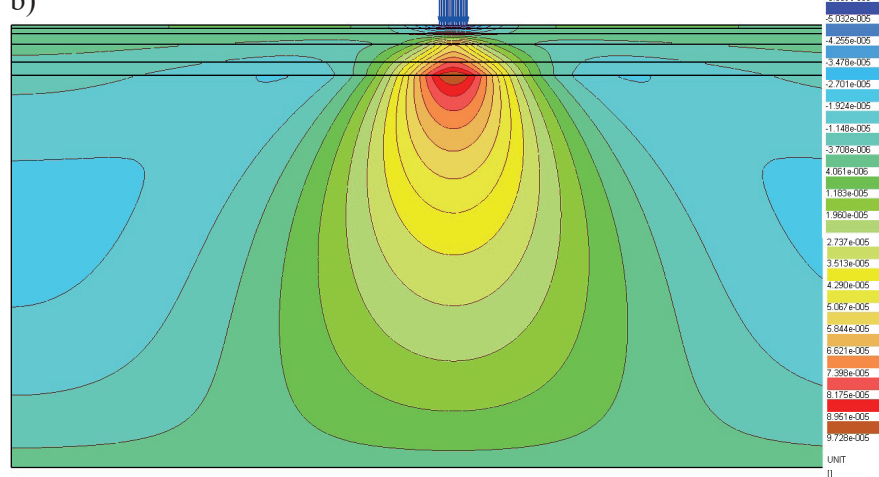

c)

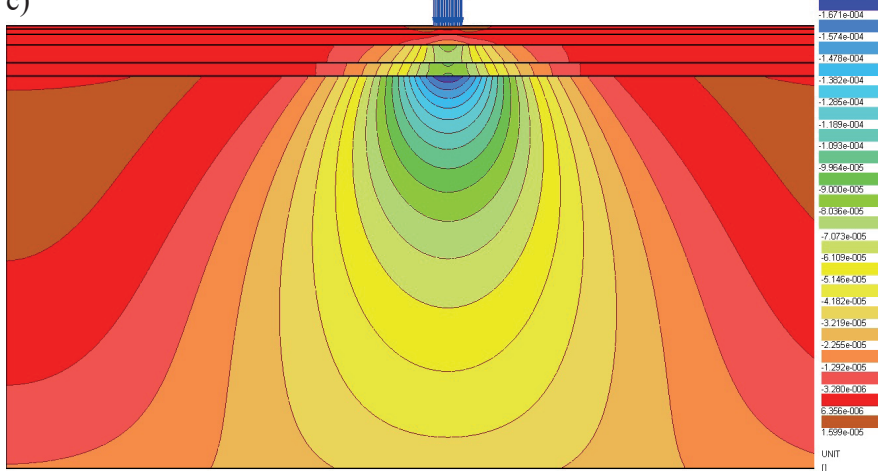

Fig. 9. Distribution of maximum vertical displacement $u_{z}$ (a), horizontal strain $\varepsilon_{x}\left(\right.$ b) and vertical strain $\varepsilon_{z}(\mathrm{c})$ registered in characteristic points of pavement for a $2 \mathrm{D}$ model 
a)

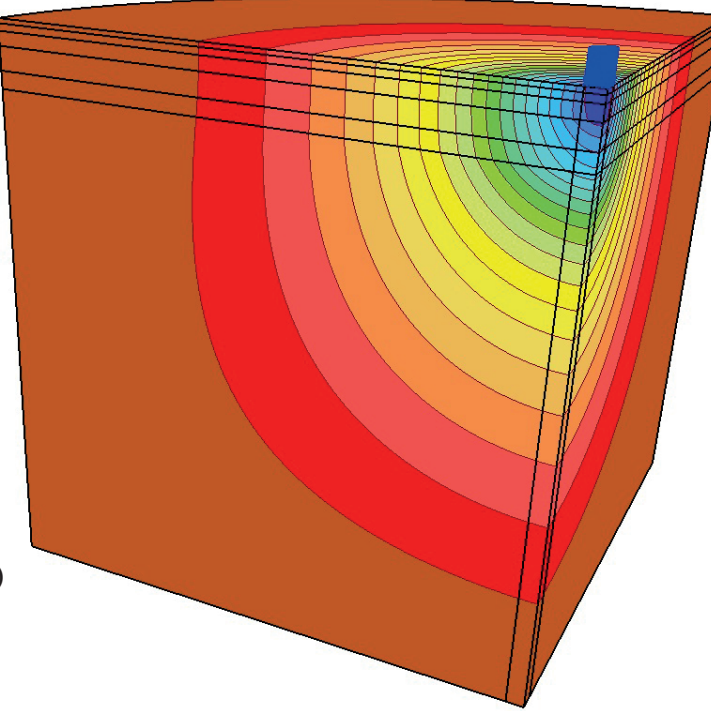

b)

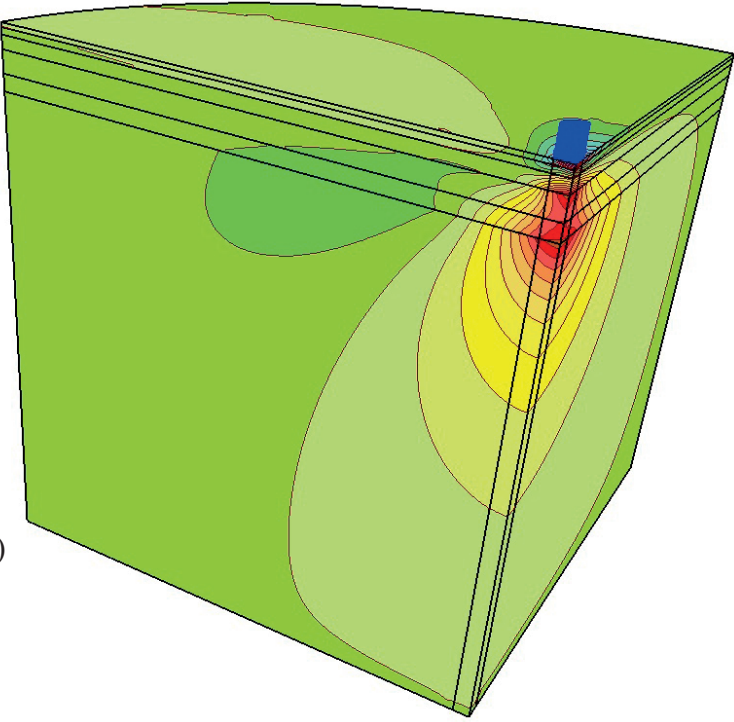

c)

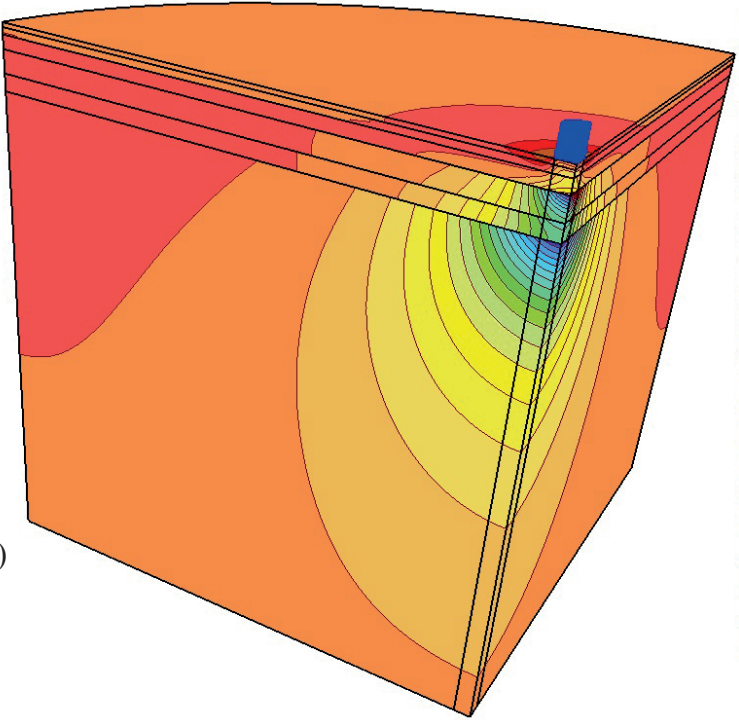

Fig. 10. Distribution of maximum vertical displacement $u_{z}$ (a), horizontal strain $\varepsilon_{x}(\mathrm{~b})$ and vertical strain $\varepsilon_{z}(\mathrm{c})$ registered in characteristic points of pavement for a 3D model state. In relation to the values obtained for the axially symmetric model, those values constitute 4 and $20 \%$, respectively.

In order to evaluate the influence of the calculation model size on the displacement and strain values in characteristic points of the system, numerical analyses have been carried out for an appropriate base (axially symmetric) model and subsequently for a model with an increased area of elastic subgrade, discretized using a FEM mesh (s1). Calculation models subject to analyses had the following dimensions:

- width: $B=2.0 ; 3.5 ; 5.0 ; 7.0 ; 10.0 \mathrm{~m}$

- height: $H=h_{p}+h_{\text {naw }}=0.42 \div 15.42 \mathrm{~m}$, where $h_{p}$ - thickness of the subgrade in range of $0.0 \div 15.0 \mathrm{~m} ; h_{\text {naw }}$ - thickness of the pavement structure, in the analyzed case equal to $0.42 \mathrm{~m}$. The results have been presented in Figs. 11-14.

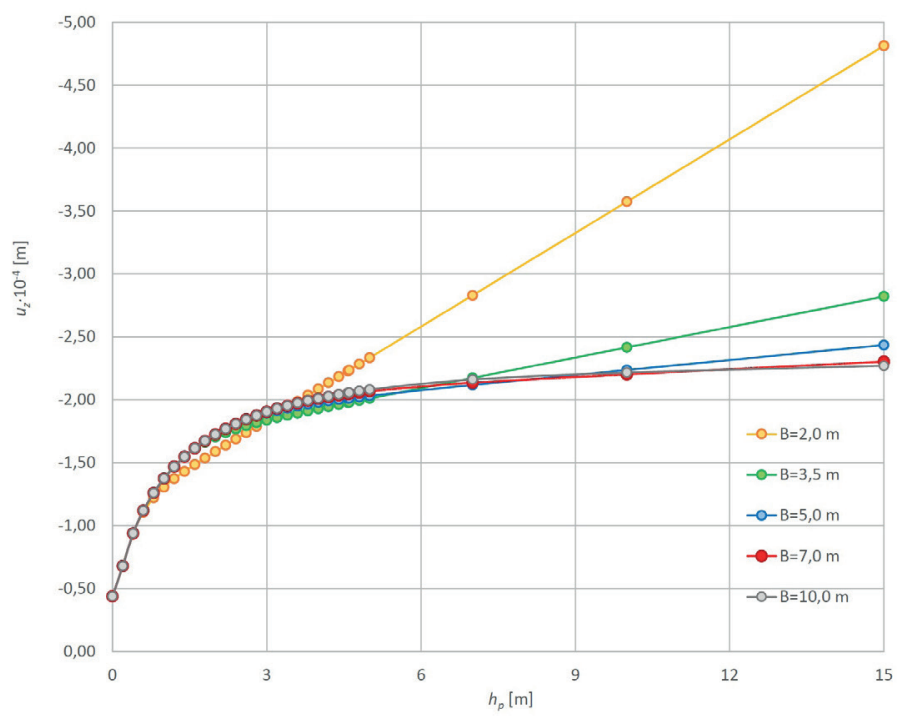

Fig. 11. Distribution of maximum vertical displacement $u_{z}$ as function of dimensions $H$ and $B$ of the adopted calculation area

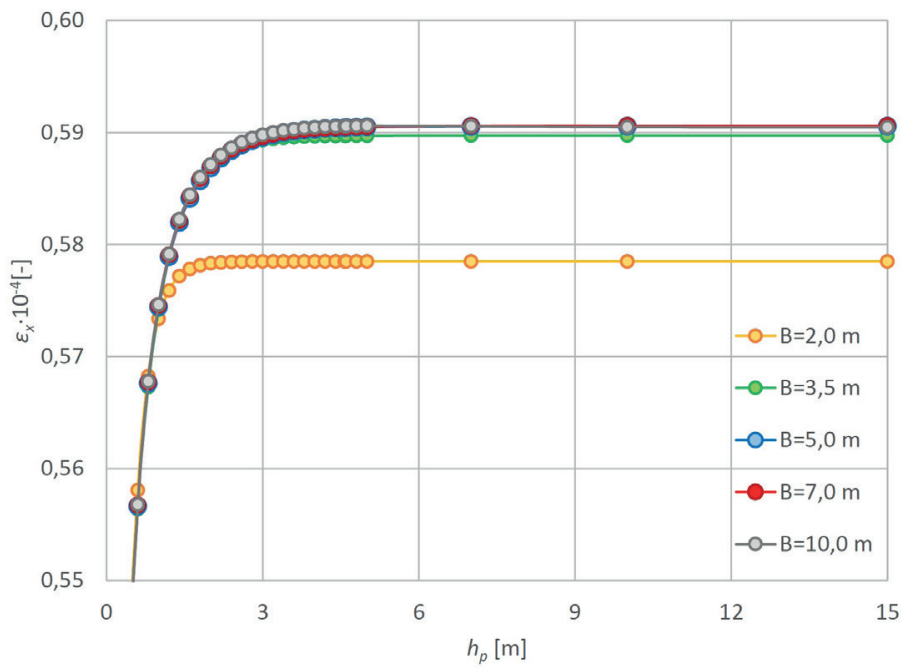

Fig. 12. Distribution of horizontal strain $\varepsilon_{x}$ at the bottom of asphalt layers as a function of dimensions $H$ and $B$ of the adopted calculation area 


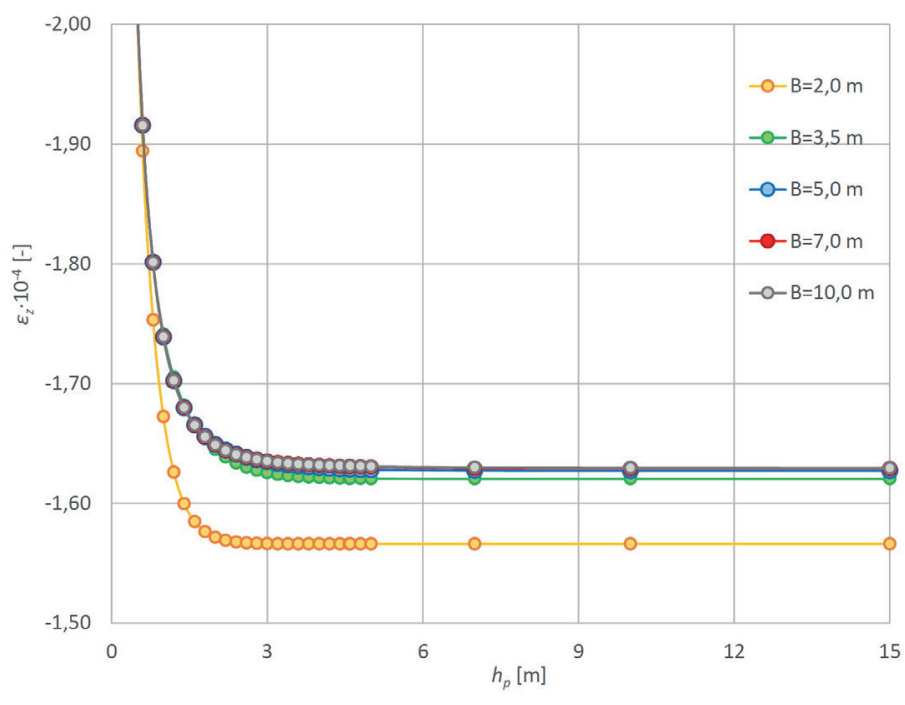

Fig. 13. Distribution of vertical strain $\varepsilon_{z}$ on top surface of improved subgrade as function of dimensions $H$ and $B$ of the adopted calculation area

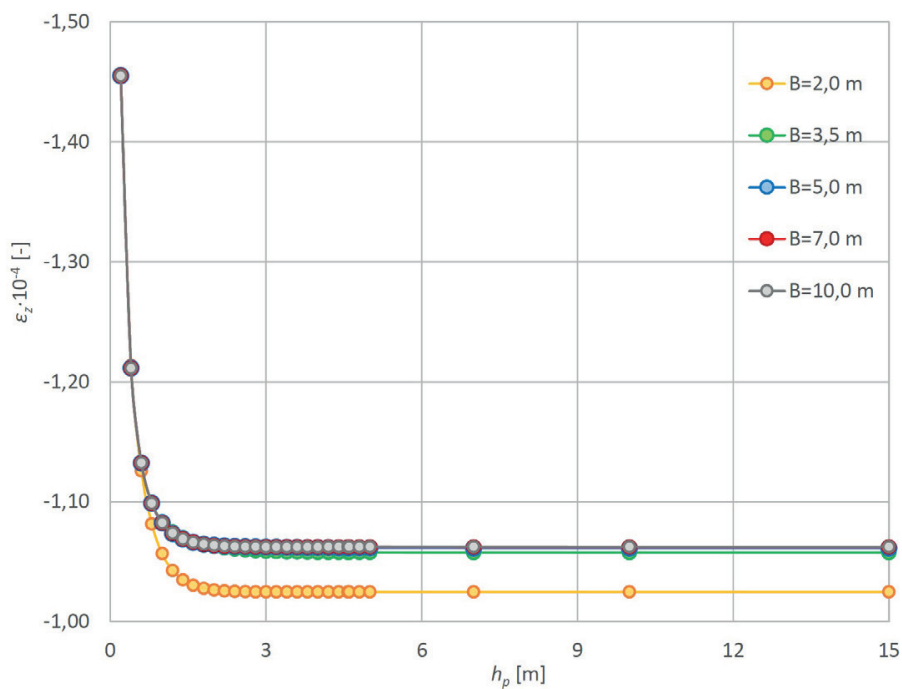

Fig. 14. Distribution of vertical strain $\varepsilon_{z}$ on top surface of natural subgrade as function of dimensions $H$ and $B$ of adopted calculation area

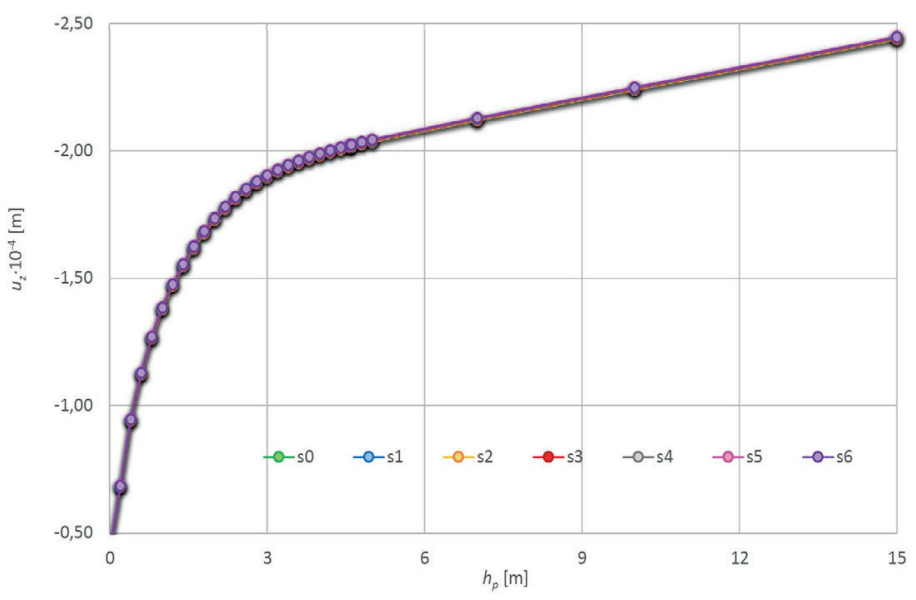

Fig. 15. Distribution of maximum vertical displacement $u_{z}$ as function of the adopted model height for different sizes of discretisation meshes
As the size of the calculation area increased, the criterion values stabilized. This fact is indicative of decreasing influence of the size of bottom subsystem, representing the natural subgrade, on the deformation to be considered in the design process. In the light of the accuracy of design criteria and considering the time of calculations related to the size of the area, a model with the dimensions of $5.0 \times 5.42 \mathrm{~m}$ was considered optimum. Consequently, that model was used for further analysis.

Further, the model of the pavement interacting with the subgrade was discretized using FEM meshes with differently sized elements. The mesh subject to analysis was made up of elements with the smallest dimension equal to 0.005 (s0); 0.02 (s2); 0.04 (s3); 0.05 (s4); $0.08 \mathrm{~m}$ (s5); $0.1 \mathrm{~m}$ (s6). The background for comparison consists of a base mesh (s1) with the smallest element dimension of $0.01 \mathrm{~m}$, see Figs. 15-18.

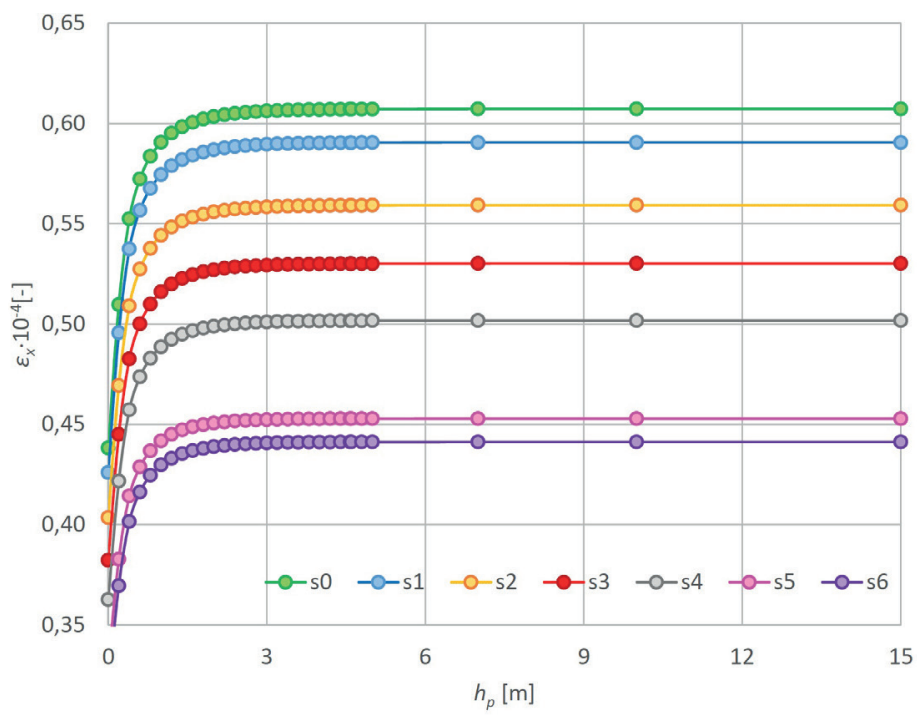

Fig. 16. Distribution of horizontal strain $\varepsilon_{x}$ in the bottom of asphalt layers as a function of the adopted model height for different sizes of discretisation meshes

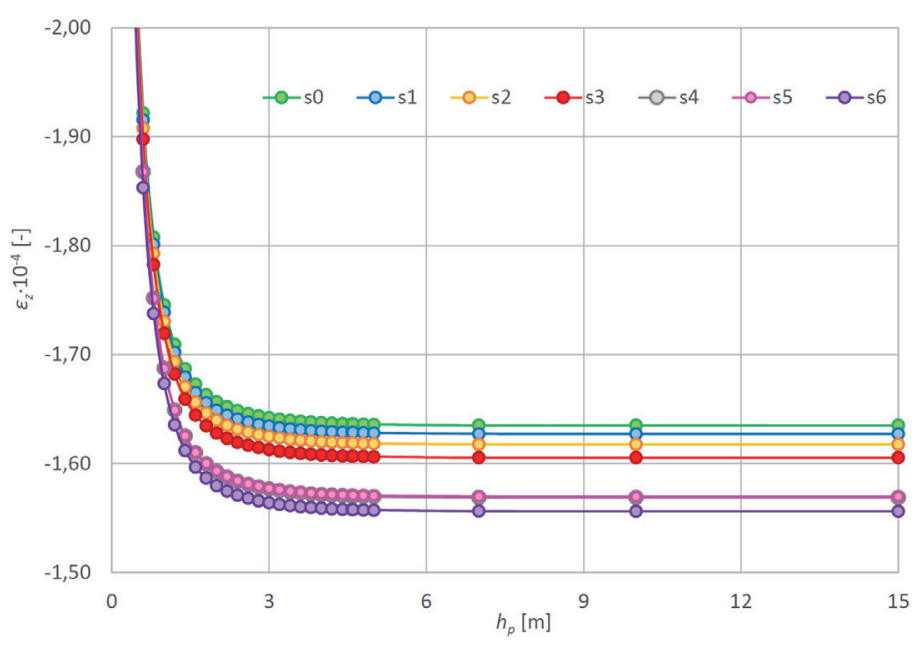

Fig. 17. Distribution of vertical strain $\varepsilon_{z}$ (c) registered on top surface of improved subgrade as a function of the adopted model height for different sizes of discretisation meshes 


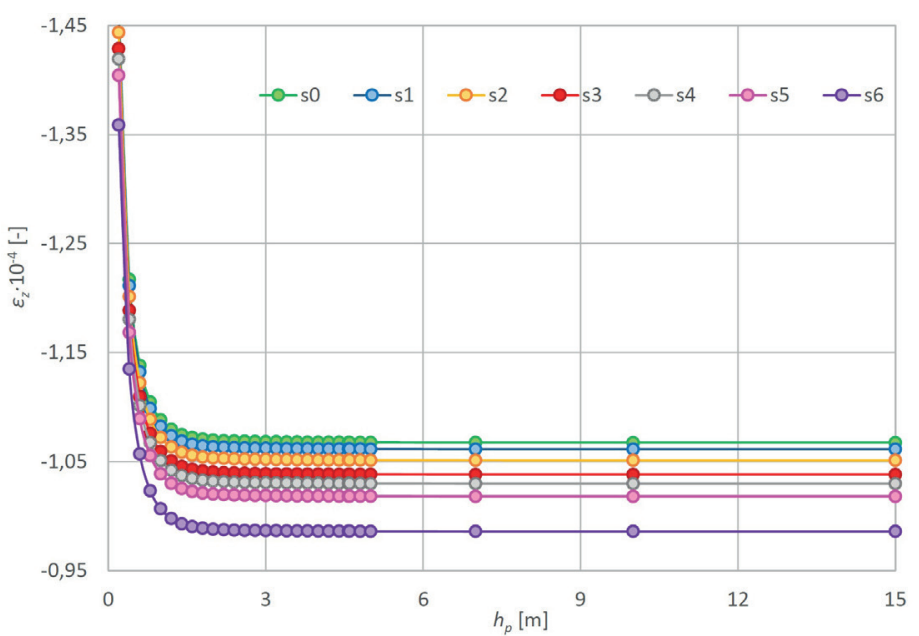

Fig. 18. Distribution of vertical strain $\varepsilon_{z}$ (c) registered ontop surface of natural subgrade as function of the adopted model height for different sizes of discretisation meshes

\section{Discussion}

On the basis of the analyses carried out using the finite element method, it can be concluded that analyses carried out in the $3 \mathrm{D}$ state allow to determine the values needed with higher precision, however a fine discretizing mesh considerably extends the calculation time. Sufficiently precise results can be achieved using the axially symmetric model.

In order to use the pavement-subgrade model with flat deformation state, it is necessary to "transfer" the load values from the axially symmetric model onto a $2 \mathrm{D}$ model. This paper demonstrates that the best fit for strains taken into consideration in the design process and state evaluations is achieved for $q^{*}=125 \mathrm{kN} / \mathrm{m}$, a value determined through trials.

It has been shown that stabilization of the values used when designing the pavement (strains $\varepsilon_{x}$ and $\varepsilon_{z}$ ) occurs for the model where subgrade thickness $h_{p} \geq 3.0 \mathrm{~m}$, and for $h_{p} \geq 2.0 \mathrm{~m}$ it can be assumed that it occurs with known accuracy ( $1 \%$ for $\varepsilon_{x} ; 1.3 \%$ $-\varepsilon_{z}$ ). For height of $h_{p}=3.0$, the accuracy of less than $1.0 \%$.

Lack of stabilization of the displacement response in the layered pavement structure-subgrade system is shown in Fig. 15. The value of maximum vertical displacement increases with the increase of subgrade thickness; there is a tendency for the influence of subgrade size to go down as the width of the adopted model increases. For subgrade that is less than $7.0 \mathrm{~m}$ in thickness, the discrepancy between results for $B=3.5 \div 10.0 \mathrm{~m}$ is negligible (up to $5.0 \%$ ).

Considering the above, it is recommended to assume a bottom subsystem of the calculation area of $5.0 \times 3.0 \mathrm{~m}$ (in this case, together with the pavement structure that area size is $5.0 \times 3.42 \mathrm{~m}$ ). In order to improve the speed of completing analyses, one may assume subgrade size of $5.0 \times 2.42 \mathrm{~m}$ with known accuracy.

It has therefore been demonstrated that calculation model sizes above c. $5.0 \mathrm{~m}$ (depending on the pavement structure thickness), as suggested in literature [13, 27], are acceptable, but time required for calculation increases together with the height of the model. At the same time, adopting subgrade thickness below $2.0 \mathrm{~m}$ [e.g. 44, 45] influences the criterion values critical for pavement fatigue life, which may lead to incorrect design or evaluation of pavement state (and design of potential overlays). Moreover, that approach automatically closes the way for thermomechanical analyses [73, 74], disabling numerical evaluation of a very important factor, i.e. the influence of temperature on the fatigue life of a pavement structure.

The factor having the greatest influence on the strain values is the size of discretization mesh elements, which is practically overlooked in literature. Unlike the maximum vertical displacement values, for which FEM results were the same regardless of mesh elements, in the case of strains, the smaller were the mesh elements, the higher were the values of strain, as per Figs. 16-18. Therefore, the size of the mesh is related to a risk of underestimating the fatigue life of the pavement.

Criterion values obtained in numerical analyses were compared to values obtained with the use of VEROAD software [27]. This specialized software determines the state of displacement, strain and stress of the pavement using analytical calculations for elastic halfspace. It should also be emphasized that the results obtained through analytic calculations using particular software such as VEROAD, BISAR or KENLAYER are also approximate, although they assume a very high accuracy [13] and therefore are considered to be accurate.

Results obtained for model height $H=5.00 \mathrm{~m}$ are presented in Table 1 . The best accuracy was achieved with the axially symmetric model discretized using a mesh (s1).

Table 1

Criterion values obtained in analyses

\begin{tabular}{|l|c|c|c|c|}
\hline \multicolumn{1}{|c|}{ Model } & $\boldsymbol{u}_{\mathrm{y}} \cdot 10^{-4}$ & $\varepsilon_{\mathrm{x}} \cdot 10^{-5}$ & \multicolumn{2}{|c|}{$\varepsilon_{\mathrm{y}} \cdot 10^{-5}[-]$} \\
\cline { 4 - 5 }$[-]$ & $\begin{array}{c}\text { improved } \\
\text { subgrade }\end{array}$ & $\begin{array}{c}\text { natural } \\
\text { subgrade }\end{array}$ \\
\hline OS(s1) B $=5.0 \mathrm{~m}$ & 2.012 & 5.094 & 1.062 & 1.629 \\
\hline OS(s0) B $=5.0 \mathrm{~m}$ & 2.012 & 6.071 & 1.068 & 1.636 \\
\hline OS(s2) B $=5.0 \mathrm{~m}$ & 2.014 & 5.592 & 1.051 & 1.619 \\
\hline OS(s3) B $=5.0 \mathrm{~m}$ & 2.017 & 5.301 & 1.038 & 1.607 \\
\hline OS(s4) B $=5.0 \mathrm{~m}$ & 2.019 & 5.016 & 1.030 & 1.570 \\
\hline OS(s5) B $=5.0 \mathrm{~m}$ & 2.024 & 4.528 & 1.018 & 1.571 \\
\hline OS(s6) B $=5.0 \mathrm{~m}$ & 2.022 & 4.412 & 0.986 & 1.558 \\
\hline OS(s1) B $=2.0 \mathrm{~m}$ & 2.230 & 5.785 & 1.025 & 1.566 \\
\hline OS(s1) B $=3.5 \mathrm{~m}$ & 1.977 & 5.897 & 1.058 & 1.621 \\
\hline OS(s1) B $=7.0 \mathrm{~m}$ & 2.046 & 5.905 & 1.062 & 1.631 \\
\hline OS(s1) B $=10.0 \mathrm{~m}$ & 2.056 & 5.906 & 1.063 & 1.631 \\
\hline 2D (s2) B $=5.0 \mathrm{~m}$ & 3.767 & 4.530 & 0.910 & 1.757 \\
\hline 3D (s2) B $=5.0 \mathrm{~m}$ & 2.007 & 5.385 & 1.045 & 1.614 \\
\hline VEROAD & 2.41 & 6.242 & 1.075 & 1.645 \\
\hline
\end{tabular}




\section{Summary}

Considering increased demands as to evaluating the behavior of engineering structures during the design process, assessing the system's behavior under existing loads, and the wide availability of computer software, it becomes necessary to use FEM numerical analyses for this purpose. However, with tendencies towards complex, 3-dimensional modelling of engineering structures, a mechanism arises to model structures as a "whole", in which the subgrade becomes a simple shape adopted in a completely arbitrary manner [42]. The size of the numerical area adopted for analysis affects the value of the model's response. In the case of layered pavement structures discussed in this paper, these are values of horizontal strain at the bottom of asphalt layers and vertical strain on the top surface of the subgrade. They constitute criteria used for design or evaluation of the state of pavement. The other analyzed parameter was the maximum vertical displacement under load; it is a parameter employed in evaluation of the state of pavement using FWD devices (or occasionally a Benkelmann beam).

For the purposes of this paper, FEM analyses were carried out on a selected flexible pavement structure. The aim of the analyses was to determine the impact of the chosen continuous model, size of the calculation area, and size of the discretization mesh on the values used for design. The paper demonstrates that large calculation areas adopted in literature $\left(h_{p} \geq 5.0 \mathrm{~m}\right)$ are justified as regards the strain response of the pavement-subgrade system, but considerably increase the calculation time, which is particularly important for $3 \mathrm{D}$ state analyses. In the case of the displacement response at the top surface of the pavement, no stabilization was observed. However, together with the increase of the width of the area, the impact of the thickness of subgrade on displacement value $u_{z}$ decreases.

The mesh chosen for the calculations has a considerable impact on the strain values, which is often overlooked in the literature regarding model description. It has been demonstrated that the finer the discretization, the higher the values of strain obtained through analysis. However, the fineness of the mesh has no influence on the vertical displacement values.

Following a comparison of the obtained values with analytic results obtained in VEROAD [27], the greatest convergence of results was obtained for the axially symmetric model, which confirms the above conclusions.

It seems reasonable to use advanced constitutive models to describe the behavior of the subsystems to assess the effect of the computational model of the multiple-layer pavement structure-subsoil system on the criterion values. This will be the subject of further research.

Acknowledgements. The work is financed by The National Centre for Research and Development within LIDER Program as a part of on-going research project "Stabilization of weak soil by application of layer of foamed concrete used in contact with subsoil” (LIDER/022/537/L-4/NCBR/2013).

\section{REFERENCES}

[1] A. Siemińska-Lewandowska, "The methods of metro tunnel construction in grounds and rocks", Geoingineering: Roads, Bridges, Tunnels 3, 76-84 (2015), [in Polish].

[2] Ł. Kaczmarek and P. Popielski, "Numerical analysis of the impact of construction of an underground metro line on the urban environment: a case study from the Vistula Valley in Warsaw", Geological Overview 64 (4), 219-229 (2016).

[3] P. Bętkowski, S. Pradelok, and M. Łupieżowiec, "Maintenance and risk assessment of a concrete frame bridge impacted by mining deformations of the area", Proc. 14th International Multidisciplinary Scientific GeoConference SGEM 2014 3, 345-352 (2014).

[4] S. Pradelok, M. Łupieżowiec, P. Bętkowski, and A. Rudzik, "Insitu testing of vibration propagation while driving the prefabricated piles", Proc. 14th International Multidisciplinary Scientific GeoConference SGEM 2014 2, 503-510 (2014).

[5] S. Ponikiewski and J. Bzówka, "Slope stability analysis of reclaimed landfill", Engineering and Construction 69 (3), 161-162 (2013), [in Polish].

[6] M. Łupieżowiec, S. Pradelok, P. Bętkowski, and G. Poprawa, "FEM model of vibration propagation in the soil caused by prefabricated driven piles". Proc. 14th International Multidisciplinary Scientific GeoConference SGEM 2014 2, 363-368 (2014), [in Polish].

[7] A.D. Mwanza, M. Muya, and H. Peiwan, "Towards modeling rutting for asphalt pavement in hot climates", in Asphalt Pavements, vol. 2, pp. 1547-1555, ed. R.Y. Kim, CRC Press Taylor\&Francis Group, London, 2014.

[8] F.T.S. Aragão and Y.R. Kim, "Modeling the effects of contituent properties on the mechanical behavior of asphalt mixtures", in Asphalt Pavements, vol. 2, pp. 1365-1374, ed. R.Y. Kim, CRC Press Taylor \& Francis Group, London, 2014.

[9] L. Fedorowicz and M. Kadela, "Model calibration of line construction-subsoil assisted by experimental research", $A G H$ Journal of Mining and Geoengineering 36 (1), 155-164 (2012).

[10] L. Fedorowicz and M. Kadela, "Problems of adequate interpretation of the results for analyses of the structure-subsoil systems", AGH Journal of Mining And Geoengineering 35 (2), 209-216 (2011), [in Polish].

[11] A. Szydło, Concrete Road Pavements. Theory. Dimensioning. Construction, Polski Cement, Kraków, 2004, [in Polish].

[12] D.L. de Jong, M.G.F. Peutz, and A.R. Korswagen, "Computer program BISAR: layered systems under normal and tangential loads", Koninklijke Shell Laboratorium Report AMSR.0006.73, (1973).

[13] R. Nagórski and M. Nagórska, "Verification of finite element models in static analysis of flexible road structures", in Collective works of Warsaw University of Technology. Civil Engineering, vol. 158, pp. 3-53, Oficyna Wydawnicza Politechniki Warszawskiej, Warsaw, 2014, [in Polish].

[14] A. Szydło, "Evaluation of pavement's bearing capacity in the light of the new catalogue", in Technological progress in road engineering. Theory and practice, pp. 21-27, ed. J. Kukiełka, Norbertinum, Lublin, 1998, [in Polish].

[15] D.H. Chen, M. Zaman, J. Laguros, and A. Soltani, “Assessment of computer programs for analysis of flexible pavement structure", Transportation Research Record 1482, 123-133 (1995).

[16] L.A. Al-Khateeb Saound and M.F. Al-Msouti, "Rutting prediction of flexible pavemenets using finite element modeling", Jordan Journal of Civil Engineering 5 (2), 173-190 (2011). 
[17] A.B. Goktepe, E. Agar, and A.H. Lav, "Advances in backcalculating the mechanical properties of flexible pavements", Advances in Engineering Software 37, 421-431 (2006), doi:10.1016/j.advengsoft.2005.10.001.

[18] M. Kadela and L. Fedorowicz, "Calculation model of layered pavement structure-subgrade system according to EC7", ACTA Scientiarum Polonorum ARCHITECTURA 12 (3), 17-25 (2013), [in Polish].

[19] H. Faheem and A. M. Hassan, "2D PLAXIS finite element modeling of asphalt-concrete pavement reinforced with geogrid", Journal of Engineering Sciences Assiut University Faculty of Engineering 42 (6), 1336-1348 (2014).

[20] M. Gwóźdź-Lasoń, "Consolidation of soil with weak layers reinforced by gravel columns and geosynthetic", Proc. 2nd Problem-solving Conference 'Interaction of structures with subgrade' 1, 231-240 (2004), [in Polish].

[21] J. Sekowski, Basics of Dimensioning Soil Improvement Pads, Silesian University of Technology Research Papers, Civil Engineering series, vol. 94, Wydawnictwo Politechniki Śląskiej, Gliwice, 2002, [in Polish].

[22] J. Fedorowicz and L. Fedorowicz, "Roads. Numerical evaluation of safety of linear structures in mining deformations risk areas", Roads. Infrastructure construction 4 (6), 37-41 (2012), [in Polish]

[23] G. Lacey, G. Thenoux, and F. Rodriguez-Roa, "Three-dimensional finite element model for flexible pavement analyses based on field modulus measurements", The Arabian Journal for Science and Engineering 33 (1B), 65-76 (2008).

[24] S.A. Perez, J.M. Balay, P. Tamagny, and Ch. Petit, "Accelerated pavement testing and modeling of reflective cracking in pavements", Engineering Failure Analysis 14, 1526-1537 (2007), doi:10.1016/j.engfailanal.2006.12.010.

[25] M. Ameri, A. Mansourian, M.H. Khavas, M.R.M. Aliha, and M.R. Ayatollahi, "Cracked asphalt pavement under traffic loading - A 3D finite element analysis", Engineering Fracture Mechanics 78, 1817-1826 (2011), doi:10.1016/j.engfracmech.2010.12.013.

[26] C. Chazallon, G. Koval, P. Hornych, F. Allou, and S. Mouhoubi, "Modelling of rutting of two flexible pavements with the shakedown theory and the finite element method", Computers and Geotechnics 36, 798-809 (2009), doi:10.1016/j.compgeo.2009.01.007.

[27] M. Kadela and M. Kozłowski, "Foamed concrete layer as sub-structure of industrial concrete floor", Proc. of WMCAUS 2016. Proc. Eng. 161C, 468-476 (2016), doi:10.1016/j. proeng.2016.08.663.

[28] R. Wardęga, "Influence of traffic structure on road structure bearing capacity", Ph.D Thesis, Wrocław University of Science and Technology, Wrocław, 2006, [in Polish].

[29] R. Nagórski, Mechanics of Road Pavement in Outline, PWN, Warsaw, 2014, [in Polish].

[30] G. Leonardi, "Finite element analysis for airfield asphalt pavements rutting prediction", Bull. Pol. Ac.: Tech. 63 (2), 397-403 (2015), doi:10.1515/bpasts-2015-0045.

[31] W. Feng, "Mechanistic-empirical study of effects of truck tire pressure on asphalt pavement performance", Ph.D Thesis, The University of Texas, Austin, 2005.

[32] P. Kanty, K. Sternik, and S. Kwiecień, "Numerical analysis of consolidation of embankment subsoil reinforced with dynamic replacement stone columns", Technical Transactions Environmental Engineering 2-Ś (24), 79-100 (2015).
[33] M. Kowalska, "Compactness of scrap tyre rubber aggregates in standard proctor test", Proc. of WMCAUS 2016. Proc. Eng. 161C, 975-979 (2016), doi:10.1016/j.proeng.2016.08.836.

[34] Catalogue of Standard Flexible and Semi-flexible Pavement Structures, ed. J. Judycki, GDDKiA, Gdańsk University of Technology, Gdańsk, 2012, [in Polish].

[35] D. Godlewski, Road Pavements, Oficyna Wydawnicza Politechniki Warszawskiej, Warsaw, 2011, [in Polish].

[36] PN-87/S/02201, "Roads. Road pavements. Classification, names, terms", 1987, [in Polish].

[37] "Guidelines for subgrade improvement in road engineering", Road and Bridge Research Institute, Warsaw, 2002, [in Polish].

[38] Catalogue of Standard Flexible Road Structures, Issue II, Studies and Materials, Vol. 21, Road and Bridge Research Institute, Warsaw, 1983, [in Polish].

[39] Catalogue of Reinforcement and Renovation of Flexible and Semi-Rigid Pavement 2012, ed. D. Sybilski, General Directorate of Public Roads, Road and Bridge Research Institute, Warsaw, 2012, [in Polish].

[40] Guide technique: Realisation des rembilais et des couches de forme. Fascicule I - Principes generaux, 2nd ed., Service d'Etudes des Techniques des Routes et Autoroutes, 2000, [in French].

[41] B. Picoux, A. El. Ayadi, and C. Petit, "Dynamic response of flexible pavement submitted by impulsive loading", Soil Dynamics and Earthquake Engineering 29, 845-854 (2009), doi:10.1016/j. soildyn.2008.09.001.

[42] S. Firlej, "Subgrade according catalogue of reinforcement and renovation of flexible and semi-rigid pavement 1997", Road Engineering 7, (1998).

[43] M. Kadela, "The criteria for modeling and analysis of layered structures-subsoil system", Ph.D Thesis, Silesian University of Technology, Gliwice, 2012, [in Polish].

[44] L. Fedorowicz, Building Structure-Subsoil Contact Task. Part I. Criteria for Modeling Process and Analyses Carried out for the Basic Contact Tasks Building Structure-Subsoil, Wydawnictwo Politechniki Śląskiej, Gliwice, 2006 [in Polish].

[45] M. Kim, "Three-dimentional finite element analysis of flexible pavements considering nonlinear pavement foundation behavior", Ph.D Thesis, University of Illinois, Urbana, 2007.

[46] S. Im, H. Ban, and Y.R. Kim, "Rutting and cracking modeling of asphalt pavements considering nonlinear viscoalasticity and cohesive zone fracture", in Asphalt Pavements, vol. I, pp. 775-783, ed. R.Y. Kim, CRC Press Taylor \& Francis Group, London, 2014.

[47] A. Ayadi, B. Picoux, G. Lefeuve-Mesgouez, A. Mesgouez, and C. Petit, "An improved dynamic model for the study of flexible pavement", Advances in Engineering Software 44, 44-53 (2012), doi:10.1016/j.advengsoft.2011.05.038.

[48] Y.R. Kim, Modelling of Asphalt Concrete, ASCE Press-McGrowHill, New York, 2009.

[49] Q. Xu and G.K. Chang, "Experimental and numerical study of asphalt material geospatial heterogeneity with intelligent compaction technology on roads", Construction and Building Materials 72, 189-198 (2014), doi:10.1016/j.conbuildmat.2014.09.003.

[50] Y.K. Seo and C.C. Swan, "Load-factor stability analysis of embankments on saturated soil deposits", Journal of Geotechnical and Geoenvironmental Engineering 127 (5), 436-445 (2001).

[51] L. Zheng, Y. Hai-lin, W. Wan-ping, and C. Ping, "Dynamic stress and deformation of layered road structure under vehicle traffic loads: Experimental measurements and numerical calculations", Soil Dynamics and Earthquake Engineering 391, 100-112 (2012). doi:10.1016/j.soildyn.2012.03.002. 
[52] Ch. Xu, Y. Anzhi, M. Liao, and T. Chunan, "Analysis of periodic in surface layer of pavement structures", Engineering Failure Analysis 18, 411-420 (2011), doi:10.1016/j.engfailanal.2010.09.023.

[53] C.M. Kuo and F.J. Chou, "Development of 3-D finite element model for flexible pavements", Journal of the Chinese Institute of Engineers 27 (5), 707-717 (2004).

[54] T. Nishiyama, M.A. Bhatti, and H.D. Lee, "Development of 3-D finite element model to quantify bond level of thin concrete overlay”, TRB 2003 Annual Meeting, (2003), CD-ROM.

[55] Y.H. Cho and H.M. Koo, "A behavior analysis of concreto overlay based on the characteristics of asphalt pavements", $82 n d$ Transportation Research Board Meeting, (2003), CD-ROM.

[56] Interim Advice Note IAN 73/06 Rev. 1, "Design guidance for road pavement foundations", (2009).

[57] J. Gaszyński and M. Gwóźdź-Lasoń, "Numerical models of the reinforced soil", Proc. 16th International Conference on Soil Mechanics and Geotechnical Engineering: Geotechnology In Harmony With The Global Environment 1-5, 799-802 (2005).

[58] M. Gryczmański and R. Uliniarz, "A simple critical state model with small strain nonlinearity for overconsolidated soils", Foundations of Civil and Environmental Engineering 12, 49-60 (2008).

[59] P.V. Lade, "Overview of constitutive models for soils", in Proceedings Soil Constitutive Models: Evaluation, Selection and Calibration Geotechnical Special Publications, No. 128, pp. 1-34, eds. J.A. Yamamuro and V. N. Kaliakin, ASCE, 2005.

[60] B. Stypułkowski, Material Issues in Road Design and Construction, Wydawnictwo Komunikacji i Łączności, Warsaw, 1981, [in Polish].

[61] A. Szydło, "Elastic characteristics of subgrade in static analysis of a road", Ph.D Thesis, Wrocław University of Science and Technology, Wrocław, 1977, [in Polish].

[62] B. Krawczyk, "Identification of parameters of road pavement models based on dynamic impulse tests", Ph.D Thesis, Wrocław University of Science and Technology, Wrocław, 2013 [in Polish].

[63] M. Kadela, "Response of subsoil on cyclic load transferred by pavement", in Proceedings Pavement Materials, Structures, and Performance Geotechnical Special Publications, No. 239, pp. 424-433, eds. B. Huang and S. Zhao, ASCE, 2014 , doi:10.1061/9780784413418.042.
[64] M.A. Elseifi, I.L. Al-Qadi, and P.J. Yoo, "Viscoelastic modeling and field validation of flexible pavements", J. Engineering Mechanics 132, 172 (2006).

[65] M.N.S. Hadi and B. Bodhinayake, "Non-linear finite element analysis of flexible pavements", Advances in Engineering Software 34, 657-662 (2003).

[66] L. Fedorowicz, J. Fedorowicz, and M. Kadela, "Evaluation of road's pavement resistance of traffic-load KR4 of category in application of the elastic-plastic model with degradation", International Conference 70 Years of FCE STU, 10 (2008), CD-ROM.

[67] M. Kadela, A. Cińcio, and M. Kozłowski, "Degradation analysis of notched foam concrete beam", Applied Mechanics and Materials 797, 96-100 (2015), doi:10.4028/www.scientific.net/ AMM.797.96.

[68] M. Kozłowski, M. Kadela, and A. Kukiełka, "Fracture energy of foamed concrete based on three-point bending test on notched beams", Proc. 7th Scientific-Technical Conference on Material Problems in Civil Engineering MATBUD'2015. Proc. Eng. 108, 349-354 (2015), doi:10.1016/j.proeng.2015.06.157

[69] H.J. Lee and Y.R. Kim, "Visci-elastic constitutive model for asphalt concrete under cyclic loading", Journal of Engineering Mechanics 1 (1), 32-40 (1998).

[70] J.E.S. Lutif, Y. Kim, F.V. Souza, and D.H. Allen, "Multiscale modeling of asphant media considering heterogeneity, viscoelasticity, and nonlinear fracture damage", in Asphalt Pavements, vol. I, pp. 943-952, ed. R.Y. Kim, CRC Press Taylor \& Francis Group, London, 2014.

[71] M. Iwański and A. Chomicz-Kowalska, "Evaluation of the pavement performance", Bull. Pol. Ac.: Tech. 63 (1), 97-105 (2015), doi:10.1515/bpasts-2015-0011.

[72] M. Kadela, "Problems in building a credible model for a system road construction-subsoil", in Selected Topics in the Field of Construction, pp. 433-442, ed. A. Wawrzynek, Wydawnictwo Politechniki Śląskiej, Gliwice, 2009, [in Polish].

[73] M. Bartoszek, L. Fedorowicz, and M. Kadela, "Numerical modeling of layered structures with aid of laboratory and in situ tests", Engineering Modelling Journal 12 (43), 15-26 (2012), [in Polish].

[74] P. Aliawdin and J. Połczyński, "Analysis of heat transfer in road pavement structures using methods of optimization", Proc. 9th International Conference "Modern Building Materials, Structures and Techniques" 3, 873-880 (2007). 